\title{
İlk Kez Afebril Nöbet Geçiren Çocuklarda Nörogörüntüleme Bulguları
}

\section{Neuroimaging Findings in Children with New-Onset Afebrile Seizure}

\author{
Altan GÜNEŞ', Dilek CEBECi²
}

1Sağlık Bilimleri Üniversitesi, Ankara Çocuk Sağlığı ve Hastalıkları Hematoloji Onkoloji SUAM, Radyoloji Bölümü, Ankara,Türkiye

${ }^{2}$ Sağlık Bilimleri Üniversitesi, Ankara Çocuk Sağlığı ve Hastalıkları Hematoloji Onkoloji SUAM, Çocuk Nöroloji Kliniği Ankara, Türkiye

Öz

Amaç: Illk kez afebril nöbet geçiren çocuklarda, anormal nörogörüntüleme bulgularını öngörmede, başta klinik bulgular olmak üzere etkili olabilecek değişkenlerin araştırıması amaçlandı.

Gereç ve Yöntemler: Çalışmamız hastane etik kurul onayı alınarak yapıldı. Ocak 2016 ile Ocak 2018 tarihleri arasında, ilk kez afebril nöbet geçirmiş, beyin bilgisayarlı tomografisi (BT) ve/veya manyetik rezonans görüntülemesi (MRG) yapılmış

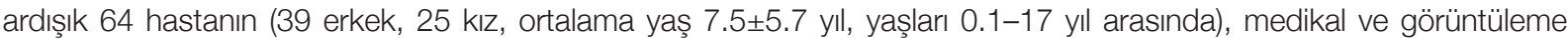
bulguları geriye dönük tarandı. Kategorik-sayısal değişkenler Ki-kare, Fisher, t-testi ile analiz edildi ve lojistik regresyon analizi yapıldı.

Bulgular: Hastaların tamamına BT çekilmiş, \%70.3'üne MRG yapılmıştı. Hastaların \% 26.6'sında BT ve MRG'de anormal bulgular, \%21.9'unda klinik olarak önemli anormal bulgular saptandı. Nöbet sayısının birden fazla olması $(p=0.031)$, nöbet açısından risk faktörünün $(p=0.025)$ ve anormal nörolojik muayenenin varlığı ( $p=0.037)$ ile klinik olarak önemli anormal nörogörüntüleme bulguları arasında anlamlı ilişki saptandı. Lojistik regresyon analizinde, anormal nörogörüntüleme bulgularını öngörmede, erkek cinsiyet $(p=0.015)$, 3 yaştan büyük olmak ( $p=0.038$ ) ve nöbet açısından risk faktörünün varlığı ( $p=0.036$ ) anlamlı bulundu. Hastaların \% 62.5'i epilepsi, \% 6.3'ü santral sinir sistemi enfeksiyonu tanısı almıştı. Hastaların \% 23.4'ünün nöbeti, ortalama 1 yıllık takip süresince tekrarlamamış ve tek afebril nöbet olarak değerlendirilmiş, \% 7.8'inde acil müdahele gerektiren anormallik saptanmıştı (kitle, kanama, iskemi).

Sonuç: İlk kez afebril nöbet geçiren çocuklarda, nöbet açısından risk faktörünün ve anormal nörolojik muayenenin varlığında, nöbet sayısının birden fazla olması durumunda yapılan nörogörüntüleme bilgilendirici olmaktadır. BT, yer kaplayan kitle ve kanama gibi acil müdahale gerektiren lezyonları göstermede olguların çoğunda yeterlidir. Klinik olarak önemli anormal bulguları göstermede MRG, uygun şartlarda çocuklarda tercih edilmesi gereken görüntüleme yöntemidir.

Anahtar Sözcükler: Afebril nöbet, Bilgisayarlı tomografi, Manyetik rezonans görüntüleme

\begin{abstract}
Objective: To evaluate the predictors of abnormal neuroimaging findings in children with new-onset afebrile seizure.

Material and Methods: The study was approved by the local ethics committee. We retrospectively reviewed the medical and imaging records of 64 consecutive patients (male/female=39/25; mean age \pm standard deviation $=7.5 \pm 5.7$ years, age ranges $0.1-17$ years) who had brain computed tomography (CT) and/or magnetic resonance imaging (MRI) between January 2016 and January 2018. Categorical and numerical variables were analyzed by Chi-square, Fisher, t-test and logistic regression analysis was performed.

Results: CT was performed in all patients and $70.3 \%$ of the patients underwent MRI. CT and MRI findings were abnormal in $26.6 \%$ of the patients. Clinically significant abnormal neuroimaging findings were found in $21.9 \%$ of the patients. There were significant relationships among the history of presence of risk factors for seizure $(p=0.025)$, more than one seizure $(\mathrm{p}=0.031)$, abnormal neurological examination $(\mathrm{p}=0.037)$ and clinically significant abnormal neuroimaging findings. In predicting abnormal neuroimaging findings in logistic regression analysis, male gender $(p=0.015)$, age over 3 years $(p=0.038)$ and presence of risk factor for seizure $(p=0.036)$ were found to be significant. Forty patients $(62.5 \%)$ had the diagnosis of epilepsy and $6.3 \%$ of the patients had the diagnosis of central nervous system infection. $23.4 \%$ of the patients' seizures did not recur over a 1-year follow-up period, so they evaluated as a single afebrile seizure and $7.8 \%$ of the patients had an emergency intervention requiring abnormalities (mass lesion, bleeding, ischemia) on neuroimaging.
\end{abstract}

Yazışma Adresi / Correspondence Address:

Altan GÜNEŞ

Sağlık Bilimleri Üniversitesi,

Ankara Çocuk Sağlığı ve Hastalıkları Hematoloji Onkoloji SUAM, Radyoloji Bölümü, Ankara, Türkiye

E-posta: altang77@gmail.com
Geliș tarihi / Received : :23.09.2018 Kabul tarihi / Accepted : 15.01.2019 Elektronik yayın tarihi : :13.03.2019 Online published

DOI: 10.12956/tchd.539057 
Conclusion: Neuroimaging is informative in children with new-onset afebrile seizure who have a risk factor for seizure, abnormal neurological examination findings and multiple seizures. CT is sufficient to show lesions in most of cases that require urgent intervention such as mass lesion and intracranial hemorrhage. MRI should be preferred in children under appropriate conditions in showing clinically important abnormal findings.

Key Words: Afebrile seizure, Computed tomography, Magnetic resonance imaging

\section{GiRiş}

Nöbet ile ilișkili semptomlar, acil servislere yapılan bașvuruların yaklașık \%1'ini olușturur (1). İlk kez afebril nöbet geçiren bir çocukta nörogörüntüleme yapmanın amacı, altta yatan ve hastanın yönetimini-prognozunu etkileyebilecek intrakraniyal patolojileri araştırmaktır. Çeşitli çalışmalarda, ilk kez afebril nöbet geçiren çocuklarda anormal nörogörüntüleme bulgularını öngörebilecek faktörler araştııımıștır. Bu çalışmalarda, postiktal nörolojik defisit, status epileptikus, hasta yaşının 6 aydan küçük olması, fokal nöbet varlığı, yeni gelişen nörolojik defisit, intrakraniyal anormalliklere yatkınlık gösteren koșulların varlığında (serebral vasküler-nörokutanöz hastalık, malignite, kafa travması, ventriküloperitoneal şant gibi) nörogörüntüleme önerilmiştir (2-4). Amerikan Nöroloji Akademisi, Amerikan Çocuk Nöroloji Derneği ve Amerikan Epilepsi Derneği tarafından yayınlanan kılavuzda, ilk kez afebril nöbet sonrası rutin nörogörüntüleme önerilmemekle birlikte bazı klinik bulguların varlığında (postiktal Todd parezisi veya nöbetten birkaç saat sonra nörolojik defisitin devamı) nörogörüntüleme önerilmektedir (5). Illk kez nöbet geçiren çocuklarda yapılan nörogörüntülemelerde \% 8 ile \% 31 arasında anormal bulgu saptandığı, bunların \% 14'ünün klinik olarak anlamlı olduğu bildirilmiştir (3-11). Nörogörüntüleme yöntemlerinden birisi olan bilgisayarlı tomografi (BT), kolay ulaşılabilirliği ve tetkik süresinin kısalığı nedeniyle acil şartlarda çoğunlukla ilk tercih edilen modalitedir (3). Manyetik rezonans görüntüleme (MRG), nöbet geçiren çocuklarda, anormallikleri saptamada daha duyarlı görüntüleme yöntemi olmakla birlikte tetkik süresinin uzunluğu, sedasyon intiyacı acil şartlarda kullanımını kısıtlamaktadır (12).

Bu çalışmada, ilk kez afebril nöbet geçiren çocuklarda, anormal nörogörüntüleme bulgularını öngörmede, bașta klinik bulgular olmak üzere etkili olabilecek değişkenlerin araştıııması amaçlandı.

\section{GEREÇ ve YÖNTEMLER}

Çalışmamız hastane etik kurul onayı alınarak yapıldı (etik kurul onay numarası: 2018-086). 1 Ocak 2016 ile 01 Ocak 2018 tarihleri arasında, 17 yaşın altında, ilk kez afebril nöbet geçirmesi nedeniyle beyin BT veya MRG çekilmiş hastalar geriye dönük olarak tarandı. Hastaların yașı, cinsiyeti, hasta geçmişinde nöbet açısından olası risk faktörlerinin varlığı, nöbet özellikleri (fokal, jeneralize), nörolojik muayene ve elektroensefalografi bulguları, hastaların son tanıları bir pediatrik nörolog (D.C.) tarafından değerlendirildi. Hastaların nörogörüntüleme tetkikleri (BT ve
MRG) bir pediatrik nöroradyolog (A.G.) tarafından, bulgulara göre normal, klinik olarak önemsiz (lateral ventriküllerde veya periferal subaraknoid mesafede hafif asimetri, nonspesifik dansite-sinyal değişiklikleri gibi) veya önemli anormal (hastanın yönetiminde veya prognozunda bir değişikliğe neden olan neoplazi, serebral vasküler hastalık, doğumsal gelişimsel anomaliler gibi) olarak kategorize edildi. Hastalardan, klinik bilgilerine ve görüntülerine ulaşılamayanlar (15 hasta), nörogörüntüleri tanısal kalitede olmayanlar (9 hasta), değerlendirmeler sonucunda klinik olarak nöbet düşünülmeyenler (23 hasta) çalışma dışında bırakıldı.

\section{Görüntüleme Tekniği}

Tüm BT görüntülemesi, 16 kesitli cihaz ile (Toshiba America Medical Systems), (100-120 kV; kesit kalınlığı $\leq 2$ mm; matriks $512 \times 512$ piksel; gantry açısı $0^{\circ}$ ) intravenöz kontrast madde kullanılmadan, hasta yașına uygun kV (<2 yaș: $100 \mathrm{kV},>2$ yaș: 120 kV) seçilerek gerçekleștirildi. Tüm MR görüntülemeler 1.5 T cihaz ile (GE Healthcare, Milwaukee, WI) çok kanallı kafa sarmalı kullanılarak çekildi. MRG, aksiyel spin-eko T1 ağırlıklı (TR/TE: 400-500/15-30 ms); aksiyel fluid-attenuated inversion recovery (TR/TE: 9000-10000/100-110 ms); aksiyel ve koronal T2 ağırlıkı (TR/TE: 4500-6000/90-110 ms), aksiyel manyetik duyarlılık (SWAN; TR/TE: 850/20 ms) ve hippokampüsün uzun aksına dik koronal 3 boyutlu T1 ağırlıklı gradient-echo (TR/TE: 2000/3.9 ms) sekansları ile elde edildi. Görüntülerin kesit kalınlığı 3 boyutlu T1 ağırlıklı görüntülemede 1 mm, diğer sekanslara ait görüntülerde ise 3 mm'di. MRG'ler, klinik olarak gerekli görülen koșulların varlığında (neoplazi, enfeksiyöz süreçler gibi) intravenöz kontrast madde kullanılarak çekildi.

\section{istatistiksel Analiz}

Kategorik değişkenler, sayı ve yüzde ile verilerek Ki-kare ve

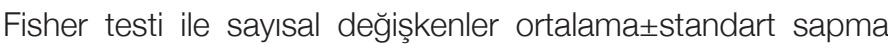
şeklinde verilerek t-testi ile analiz edildi. Normal ve klinik olarak önemsiz anormal nörogörüntüleme bulgularının her ikisi birlikte "normal" olarak gruplandırılı. Anormal nörogörüntüleme bulguları öngörmede, hastaları yüksek veya düşük riskli gruplara ayıran değişkenleri tanımlamak için lojistik regresyon analizi yapıldı. Analiz edilen değişkenler; yaş (12,18,24 veya 36 ay), cinsiyet, nöbet açısından risk faktörünün varlığı (prematürite, kafa travması, nörokutanöz-kronik hastalık), 24 saat içindeki nöbet sayısı ( 1 veya $>1$ ) ve süresi (5 dakikadan az veya çok), fokal nöbet varlığı, anormal nörolojik muayene veya elektroensefalografide anormal bulgu varlığıydı. Tüm analizler SPSS ile (versiyon 22.0, SPSS Inc.,Chicago, IL) yapıldı ve $\mathrm{p}<0,05$ istatistiksel olarak anlamlı kabul edildi. 


\section{BULGULAR}

Çalışmaya yaşları 0.1 ile 17 arasında değişen (ortalama yaşıstandart sapma, $7.5 \pm 5.7 \mathrm{yll}$ ) ardışık 64 çocuk (39 erkek, $25 \mathrm{kIz}$ ) dahil edildi (Tablo I). Kızlar (7.7 \pm 5.7 yaş) ile erkeklerin (7.4 \pm 5.8 yaş) ortalama yaşları arasında anlamlı farkllık saptanmadı ( $p=0,870$, t-test).

Hastaların tamamına BT, \%70.3'üne (45/64) MRG çekilmişti. Hastaların \%26.6'sında (17/64) BT ve MRG'de anormal nörogörüntüleme bulguları, \%21.9'unda (14/64) klinik olarak

Tablo I: Hastaların demografik, klinik ve nörogörüntüleme bulguları.

\begin{tabular}{|l|c|}
\hline Toplam & $\mathbf{6 4}$ hasta \\
\hline Erkek/Kız & $39 / 25$ \\
\hline Yaş, yıl & \\
\hline Erkek & $7.4 \pm 5.8(0.2-17)$ \\
\hline Kız & $7.7 \pm 5.7(0.1-17)$ \\
\hline Anormal nörolojik muayene,\% & $13(20.3)$ \\
\hline Nörolojik defisit & $4(6.2)$ \\
\hline Bilinç değişikliği & $8(12.5)$ \\
\hline Motor gelişim geriliği & $4(6.2)$ \\
\hline Risk faktörü,\% & $12(18.7)$ \\
\hline Preterm & $6(9.4)$ \\
\hline Kafa travması & $2(3.1)$ \\
\hline Kronik hastalık & $4(6.2)$ \\
\hline Nöbet tipi, \% & $56(87.5)$ \\
\hline Fokal & $41(73.2)$ \\
\hline Jeneralize & $15(26.8)$ \\
\hline Nöbet sayısı, \% & \\
\hline 1 & $30(46.9)$ \\
\hline$>1$ & $34(53.1)$ \\
\hline Nöbet süresi, \% & \\
\hline$<5$ dakika & $44(68.8)$ \\
\hline$>5$ dakika & $20(31.2)$ \\
\hline Elektroensefalografi, \% & $51(79.7)$ \\
\hline Normal & $24(47.1)$ \\
\hline Anormal & $27(44.3)$ \\
\hline BT, \% & $64(100)$ \\
\hline Normal & $54(84.4)$ \\
\hline Anormal & $10(15.6)$ \\
\hline MRG, \% & $45(70.3)$ \\
\hline Normal & $30(66.7)$ \\
\hline Anormal & $15(33.3)$ \\
\hline Nörogörüntüleme, \% & \\
\hline Normal & $45(23.4)$ \\
\hline Anormal & $47(73.4)$ \\
\hline Tek afebril nöbet & $17(26.6)$ \\
\hline
\end{tabular}

önemli anormal nörogörüntüleme bulguları saptandı (Tablo I ve II) (Şekil 1). Nörogörüntüleme bulguları, BT'de hastaların \%84.4'ünde (54/64) ve MRG'de \%66.7'sinde (30/45) normaldi (Tablo I). Hastaların \%15.6'sında (10/64) BT'de, \% 26.7'sinde (12/45) ise MRG'de klinik olarak önemli anormal nörogörüntüleme bulgular mevcuttu (Tablo II). BT'si normal olarak değerlendirilen ve MRG yapılan 7 hastanın 3'ünde (\% 42.8) klinik olarak önemsiz (fokal T2 sinyal artışı [2 hastada], gelişimsel venöz anomali [1 hastada]), 4'ünde (\%57.2) önemli anormal nörogörüntüleme bulguları (hipoglisemi ve hipoksik iskemik ensefalopati sekeli, posterior reversible ensefalopati, band ve nodüler heterotopi) izlendi (Șekil 2,3).

Klinik olarak önemli anormal nörogörüntüleme bulguları ile aynı gün içinde geçirilen nöbet sayısının birden fazla olması ( $p=0.031$, Ki-kare testi), nöbet açısından risk faktörünün varlığı (prematürite, kafa travması, kronik hastalık [immün yetmezlik, dikkat eksikliği, Diamond Blackfan]) ( $p=0.025$, Fisher test) ve nörolojik muayenenin anormal olması $(p=0.037$, Fisher test) arasında anlamlı ilişki saptandı. Nöbetin fokal olması $(p=0,468$, Fisher test), nöbet süresi ( $p=1$, Fisher test), anormal
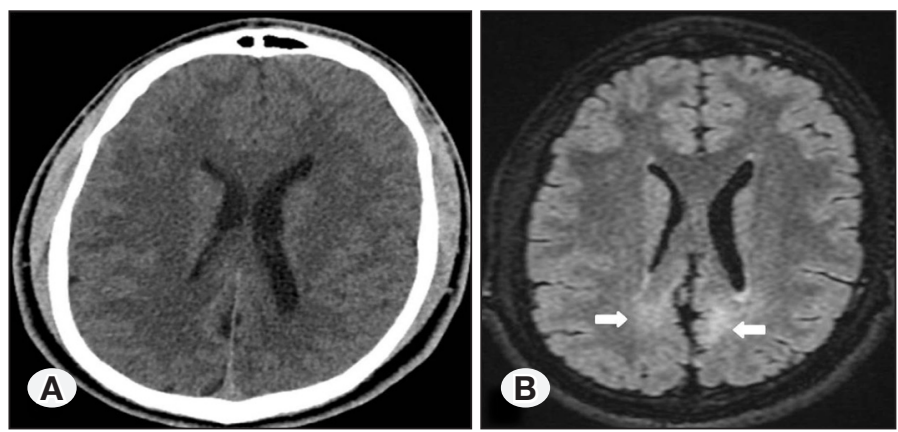

Şekil 1: 2 yaşında erkek hastada hipoglisemi sekeli. A) Aksiyel beyin bilgisayarlı tomografi kesitinde bilateral paryetal loblarda anormal bulgu izlenmiyor. B) Beyin omurilik sıvısının baskılandığı aksiyel FLAIR manyetik rezonans görüntüde, hipoglisemi sekeline bağlı bilateral paryetal korteks-subkortikal beyaz cevherde anormal sinyal artışı görülüyor (oklar).
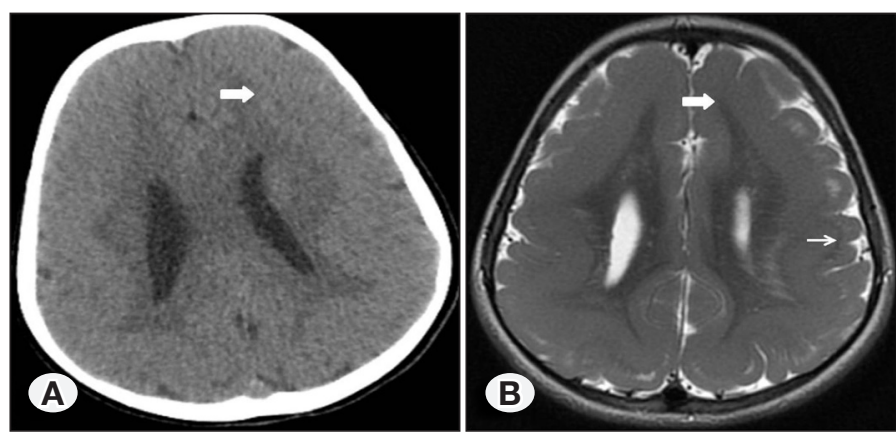

Şekil 2: 3.5 yaşında kız hastada pakigri ve band heterotopi.

A) Aksiyel beyin bilgisayarlı tomografi (BT) kesitinde bilateral serebral kortekste kalınlık artışı (ok) ile birlikte giruslarda düzleşme izleniyor. B) Sıvıya duyarlı aksiyel T2 ağırlıklı manyetik rezonans görüntüde, BT'ye benzer Şekilde pakigri ile uyumlu giruslarda düzleşme-sulkuslarda azalma görülüyor. Ancak BT'de kortikal kalınlık artışı şeklinde izlenen alanların, periferal beyaz cevherin altında (ince ok) bant heterotopiye bağlı olduğu görülüyor (kalın ok). 
Tablo II: Hastaların nörögörüntülemelerindeki anormal bulguları.

\begin{tabular}{|c|c|c|c|c|c|}
\hline & Cinsiyet & Yaş, yıl & Anormal nörogörüntüleme & BT & MRG \\
\hline $1^{*}$ & $\mathrm{KIZ}$ & 3.5 & Band heterotopi, pakigri & anormal & anormal \\
\hline 2 & $\mathrm{KIz}$ & 1.5 & Hipoksik iskemik ensefalopati & normal & anormal \\
\hline $4^{*}$ & Erkek & 9 & Nodüler heterotopi & normal & anormal \\
\hline 5 & Erkek & 1.5 & İntrakraniyal kanama & anormal & anormal \\
\hline 7 & KIZ & 6 & Poransefali & anormal & anormal \\
\hline 8 & Erkek & 1 & Korpus kallozum disgenezisi & anormal & anormal \\
\hline 9 & Erkek & 13 & ICA disseksiyonu, akut iskemi & anormal & anormal \\
\hline 10 & Erkek & 15 & Intrakraniyal kanama & anormal & yok \\
\hline 11 & Erkek & 2.5 & İntrakraniyal kanama & anormal & yok \\
\hline $15^{\star *}$ & Erkek & 6 & Korpus kallozum disgenezisi, pakigri & anormal & anormal \\
\hline 16 & Erkek & 8 & Posterior reversible ensefalopati & normal & anormal \\
\hline 17 & Erkek & 1 & Korpus kallozum disgenezisi & anormal & anormal \\
\hline
\end{tabular}

BT: bilgisayarlı tomografi, MRG: manyetik rezonans görüntüleme, *: BT'de band ve nodüler heterotopi görülemedi, **: BT'de pakigri görülemedi, ICA: internal karotis arter.
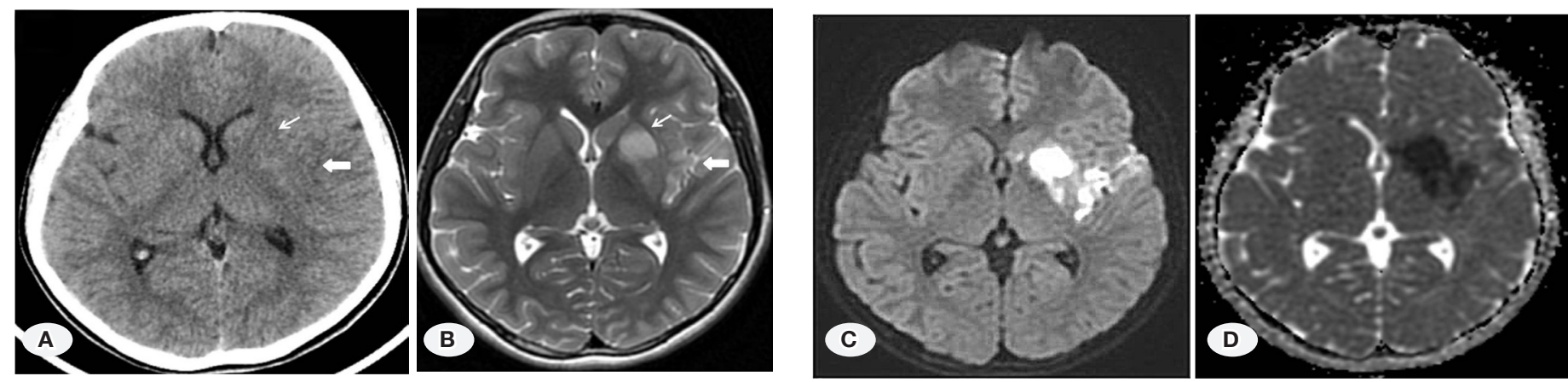

Şekil 3: 13 yaşında erkek hastada akut iskemi. A) Aksiyel beyin bilgisayarlı tomografi (BT) kesitinde, sol putamenin anteriorunda (ince ok) ve insuler korteks-beyaz cevher dansitesinde (kalın ok) azalma görülüyor. Aksiyel T2 ağırlıklı manyetik rezonans görüntüde (B), difüzyon ağırlıklı görüntülemede (C, D), BT’ye benzer Şekilde akut iskemi ile uyumlu kısıllanmış difüzyon ve anormal sinyal değişikliği izleniyor (ince ve kalın oklar).

elektroensefalografi bulguları ( $\mathrm{p}=1$, Fisher test) ile klinik olarak önemli anormal nörogörüntüleme bulguları arasında anlamlı ilişki saptanmadı.

Hastaların yaşları 4 farklı gruba ayrılarak ( $<12$ ay->12 ay, $<18$ ay->18 ay, $<24$ ay->24 ay ve <36 ay->36 ay) klinik olarak önemli anormal nörogörüntüleme bulguları arasındaki ilişki değerlendirildi. Hasta yaşı ile anormal nörogörüntüleme bulguları arasındaki anlamlı sonuç saptanmadı ( $p \geq 0.731$, Fisher test). Klinik parametreler ile anormal nörogörüntüleme arasındaki lojistik regresyon analizinde; erkek cinsiyet ( $p=0.015)$, yaşın 3 'ün üzerinde olması $(p=0.038)$ ve nöbet açısından risk faktörünün varlığı ( $p=0.036$ ) anlamlı bulundu (duyarlılık \%83.3, özgüllük \% 97.1). Analiz ile anlamlı bulunan bu parametrelere sahip olmayan hastalarda, anormal nörogörüntüleme bulgusu izlenmedi.
Çalışmaya dahil edilen olguların \% 92'sinin ortalama 6-12 ay süreli klinik takipleri mevcuttu. Hastaların \%62.5'i epilepsi, \% 6.3'ü santral sinir sistemi enfeksiyonu tanısı alarak tedavileri düzenlenirken, \%7.8'inde acil müdahele gerektiren anormal nörogörüntüleme bulgusu saptandı (kitle, intrakraniyal kanama, iskemi). Hastaların \%23.4'ünün izleminde nöbetin tekrarlamaması nedeniyle geçirdikleri nöbet, tek afebril nöbet olarak değerlendirildi.

\section{TARTIŞMA}

Illk kez afebril nöbet geçiren çocuklarda nörogörüntüleme yöntemlerinin hangi semptom ve/veya klinik bulguların varlığında kullanılacağı net değildir. Çalışmamızdaki anormal 
nörogörüntüleme bulgularının oranı (\%26.6), literatürdeki bazı çalışmalardan yüksek, bazılarından ise düşüktü (\%8-33 arasında) $(3,13)$. Afebril nöbet geçiren çocukların değerlendirilmesinde çoğunlukla ilk tercih edilen görüntüleme yöntemi olan BT, çalısmamızda da hastaların tamamında kullanılan illk yöntemdi. Çalışmamızda BT'de saptanan intrakraniyal kanama, laküner olmayan iskemi, kitle ve korpus kallozum disgenezis bulguları MRG ile de doğrulanmış olup BT, sıralanan anormalliklerin saptanmasında başarlıydı. Ancak BT'lerinin normal olarak değerlendirildiği 7 olgunun 4'ünde klinik olarak önemli bir anormallik (heterotopi, hipoksik iskemik ensefalopati, posterior reversible ensefalopati, hipoglisemi sekeli) izlendi. Çalışmamızda MRG, önceki çalısmalara benzer Şekilde, özellikle heterotopi gibi doğumsal anormallikleri, hipoglisemi sekeli gibi BT ile fark edilmesinin zor olduğu sekel değişiklikleri göstermede daha duyarlıydı $(5,14)$.

Illk kez afebril nöbet geçiren çocuklarda yapılan çalışmalarda, anormal nörogörüntüleme bulgularının fokal nöbeti olan ve/veya daha küçük yaştaki çocuklarda (bir çalışmada <18 ay, diğer bir çalışmada <33 ay) daha sık olarak saptandığı bildirilmiştir (3, $8,15,16)$. Çalışmamızda farklı yaş grupları ile önemli anormal nörogörüntüleme bulguları arasında istatistiksel olarak anlamlı ilişki bulamazken, lojistik regresyon analizinde hasta yaşının 3'den büyük olması anormal nörogörüntüleme bulguları açısından risk faktörü olarak saptandı. Çalışmamızda klinik olarak önemli anormal nörogörüntüleme bulguları ile nöbetin fokal özellikler göstermesi arasındaki ilişki istatistiksel olarak anlamlı değildi. Bunun nedeni fokal nöbetin hızlı bir Şekilde sekonder jeneralizasyon göstererek bilateral tonik klonik nöbete ilerlemesi ve nöbet başlangıcındaki fokal bulguların gözden kaçırımış olması olabilir. Ancak çalışmamızda fokal nöbet geçiren hastalarımızda, literatüre göre (\%13) daha yüksek oranda (\%17) klinik olarak önemli nörogörüntüleme bulguları saptandı (3). Elektroensefalografinin normal olması olası nörolojik anormalliği veya hastalığı ekarte ettirmemekle birlikte anormal olması intrakraniyal patoloji varlığı veya nöbetlerin tekrarlaması bakımından fikir verebilir $(12,17)$. Çalışmamızda anormal elektroensefalografi bulguları, nöbet sayısı ile anormal nörogörüntüleme bulguları arasında anlamlı ilişki saptanmadı. Çalışmalarda status epileptikus ile başvuran çocukların \%29 ile \%49'ında anormal nörogörüntüleme bulgularının izlendiği bildirimiştir (4,14). Amerikan Nöroloji Akademisi, status epileptikusta nörogörüntüleme yapmak için yeterli kanıt olmadığını bildirirken, ILAE (International League Against Epilepsy) kllavuzu nörogörüntülemeyi önermektedir $(18,19)$. Çalışmamızda, nöbet süresi 5 dakikadan uzun olan hastalarda, önceki çalışmalardan daha düşük oranda (\%15) önemli anormal nörogörüntüleme bulguları (kronik iskemik lezyon, kitle, intrakraniyal kanama) saptandı. Bu hastalarda acil müdahale gerektiren klinik olarak önemli anormal nörogörüntüleme bulgularının görülme oranı ise \%10'du. Bu durum, Amerikan Nöroloji Akademisi'nin tavsiyesini destekler biçimde, status epileptikus varlığında nörogörüntüleme yapılmasını önerecek düzeyde istatistiksel olarak anlamlı bir ilişki değildi $(14,20)$.
Çalışmamızda uzun süreli postiktal nörolojik defisiti olan bir hastamızda, daha önceki çalışmalara benzer Şekilde önemli nörogörüntüleme bulgusu saptandı $(21,22)$. Literatür ile uyumlu olarak çalışmamızda, nöbet sayısının birden fazla olması, nöbet açısından risk faktörü ve anormal nörolojik muayene varlığı ile klinik olarak önemli anormal nörogörüntüleme bulguları arasında anlamı ilişki saptandı $(3,8,23)$. Çalışmamızdaki lojistik regresyon analizine göre saptadığımız değişkenlere (3 yaşın üzerinde, risk faktörü saptanan erkek hasta) sahip hastalarımızda, anormal nörogörüntüleme bulgusunun izlenmesi yüksek duyarlllik ve özgüllüğe sahipti. Bulgularımıza göre fokal nöbet ve status epileptikus ile klinik olarak önemli nörogörüntüleme bulguları arasında istatistiksel anlamlı ilişki olmasa da her iki durum varlığında, nörogörüntüleme bulgularının önemli olma eğiliminde olduğu düşünüldü.

Çalışmamızda, daha önceki çalışmalara benzer Şekilde ilk kez afebril nöbet sonrası anormal nörogörüntüleme bulgularını öngörmede anlamlı olabilecek faktörler irdelendi. Literatürde ilk afebril nöbet sonrasında rutin nörogörüntüleme önerilmemektedir. Çalışmadaki amacımız, ilk kez afebril nöbet geçiren ve nörogörüntülemesi yapılmış hastalardaki bulguları araştırmakolduğundan, hastalarıntamamınınnörögörüntülemesi vardı. Çalışmamızda intrakraniyal anormallikleri göstermede daha duyarlı olan MRG'nin her hastada çekilememiş olması bir kısıtlama olabilir. Çalışmamızın güçlü tarafı ise hastalarımızın büyük kısmının klinik takiplerinin olmasıdır.

Sonuç olarak, ilk kez afebril nöbet geçiren çocuklarda, nöbet açısından risk faktörünün ve anormal nörolojik muayenenin varlığında, nöbet sayısının birden fazla olması durumunda yapılan nörogörüntülemenin bilgilendirici olduğu sonucuna vardık. Kolay ulaşılabilen ve görüntüleme süresi kısa olan BT, intrakraniyal kanama, kitle gibi anında müdahale gerektiren anormallikleri göstermede olguların büyük kısmında yeterli gözükmektedir. Ancak BT kadar kolay ulaşılamaması, küçük çocuklarda sedasyon gerektirmesi ve nispeten uzun tetkik süresine sahip olmasına rağmen MRG, uygun şartlarda çocuklarda tercih edilmesi gereken görüntüleme yöntemidir.

\section{KAYNAKLAR}

1. Chen CY, Chang YJ, Wu HP. New-onset seizures in pediatric emergency. Pediatr Neonatol 2010;51:103-11.

2. Warden CR, Brownstein DR, Del Beccaro MA. Predictors of abnormal findings of computed tomography of the head in pediatric patients presenting with seizures. Ann Emerg Med 1997;29:51823.

3. Sharma S, Riviello JJ, Harper MB, Baskin MN. The role of emergent neuroimaging in children with new-onset afebrile seizures. Pediatrics 2003;111:1-5.

4. Garvey MA, Gaillard WD, Rusin JA, Ochsenschlager D, Weinstein $\mathrm{S}$, Conry JA, et al. Emergency brain computed tomography in children with seizures: who is most likely to benefit? J Pediatr 1998;133:664-9. 
5. Hirtz D, Ashwal S, Berg A, Bettis D, Camfield C, Camfield P, et al. Practice parameter: evaluating a first nonfebrile seizure in children: report of the quality standards subcommittee of the American Academy of Neurology, The Child Neurology Society, and The American Epilepsy Society. Neurology 2000;55:616-23.

6. Berg AT, Testa FM, Levy SR, Shinnar S. Neuroimaging in children with newly diagnosed epilepsy: a community based study. Pediatrics 2000;106:527-32.

7. Shinnar S, O'Dell C, Mitnick R, Berg AT, Moshe SL. Neuroimaging abnormalities in children with an apparent first unprovoked seizure. Epilepsy Res 2001;43:261-9.

8. Maytal J, Krauss JM, Novak G, Nagelberg J, Patel M. The role of brain computed tomography in evaluating children with new onset of seizures in the emergency department. Epilepsia 2000;41:9504.

9. Gaillard WD, Chiron C, Cross JH, Harvey AS, Kuzniecky R, HertzPannier L, et al. International League Against Epilepsy, Committee for Neuroimaging, Subcommittee for Pediatric. Guidelines for imaging infants and children with recent-onset epilepsy. Epilepsia 2009;50:2147-53.

10. Harden CL, Huff JS, Schwartz TH, Dubinsky RM, Zimmerman RD, Weinstein S, et al. Therapeutics and Technology Assessment Subcommittee of the American Academy of Neurology. Reassessment: neuroimaging in the emergency patient presenting with seizure (an evidence-based review): report of the Therapeutics and Technology Assessment Subcommittee of the American Academy of Neurology. Neurology 2007;69:1772-80.

11. Kalnin AJ, Fastenau PS, deGrauw TJ, Musick BS, Perkins SM, Johnson CS, et al. Magnetic resonance imaging findings in children with a first recognized seizure. Pediatr Neurol 2008;39:404-14.

12. Ghazala QS, Phyllis LH. Afebrile Pediatric Seizures. Emerg Med Clin North Am 2011;29:95-108.

13. Al-Shami R, Kair AM, Elseid M, Ibrahim K, Al-Ahmad A, Elsetouhy $A$, et al. Neuroimaging evaluation after the first afebrile seizure in children: a retrospective observational study. Seizure 2016;43:2631.
14. Singh RK, Stephens S, Berl MM, Chang T, Brown K, Vezina LG, et al. Prospective study of new-onset seizures presenting as status epilepticus in childhood. Neurology 2010;74:636-42.

15. Aprahamian N, Harper MB, Prabhu SP, Monuteaux MC, Sadiq $Z$, Torres A, et al. Pediatric first time non-febrile seizure with focal manifestations: is emergent imaging indicated? Seizure 2014;23:740-5.

16. McAbee GN, Barasch ES, Kurfist LA. Results of computed tomography in "neurologically normal" children after initial onset of seizures. Pediatr Neurol 1989;5:102-6.

17. Shinnar S, Berg AT, Moshe SL, O’Dell C, Alemany M, Newstein $D$, et al. The risk of seizure recurrence after a first unprovoked afebrile seizure in childhood: an extended follow-up. Pediatrics 1996;98:216-25.

18. Riviello JJ, Ashwal S, Hirtz D, Glauser T, Ballaban-Gil K, Kelley K, et al. Practice parameter: diagnostic assessment of the child with status epilepticus (an evidence-based review): report of the Quality Standards Subcommittee of the American Academy of Neurology and the Practice Committee of the Child Neurology Society. Neurology 2006 67:1542-50.

19. Beghi E, De Maria G, Gobbi G, Veneselli E. Diagnosis and treatment of the first epileptic seizure: guidelines of the Italian League against Epilepsy. Epilepsia 2006;47:2-8.

20. Todd WL, Kara BJ, Kenneth AM, Lise EN, Tobias L, Sanjay PP, et al. Yield of Emergent Neuroimaging in Children with New-Onset Seizure and Status Epilepticus. Seizure 2016;35: 4-10.

21. Ferry PC. Pediatric neurodiagnostic tests: a modern perspective. Pediatr Rev 1992;13:248-55.

22. Vining EP, Freeman JM. Management of nonfebrile seizures. Pediatr Rev 1986;8:185-90.

23. Bautovich T, Numa A. Role of head computed tomography in the evaluation of children admitted to the paediatric intensive care unit with new-onset seizure. Emerg Med Australas 2012;24:313-20. 